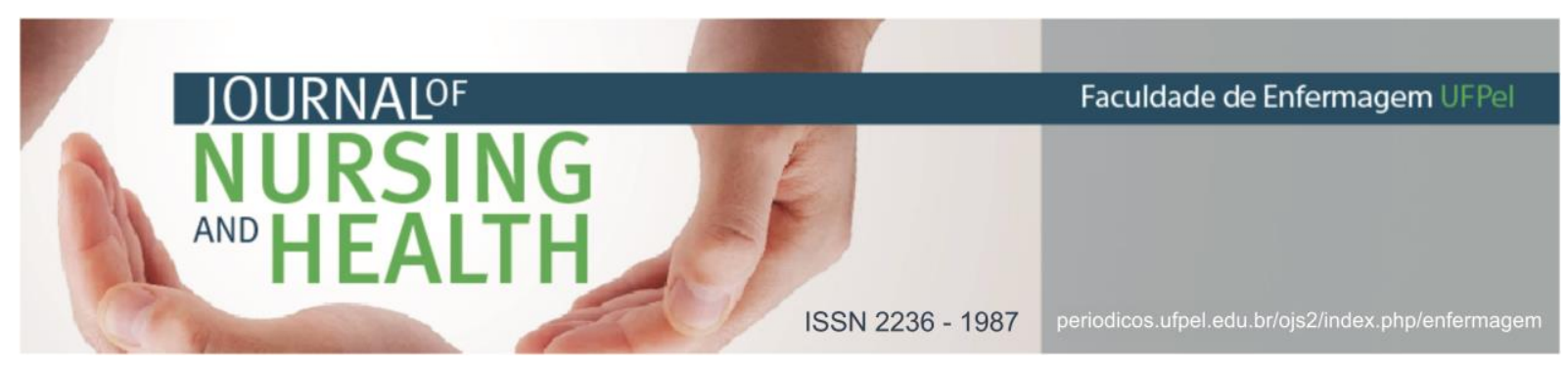

ARTIGO ORIGINAL

\title{
Sentimentos gerados na família pela internação hospitalar da criança
}

\author{
Feelings generated in the Family by child's hospitalization
}

\section{Sentimientos generados en la familia por la internación hospitalaria del niño}

Costa, Aline Rodrigues; Nobre, Camila Magroski Goulart²; Gomes, Giovana Calcagno³ Nornberg, Pamela Kath de Oliveira ${ }^{4}$; Rosa, Gabriela Silva Miranda ${ }^{5}$

Como citar este artigo: Costa AR, Nobre CMG, Gomes GC, Nornberg PKO, Rosa GSM. Sentimentos gerados na família pela internação hospitalar da criança. J. nurs. health. 2019;9(2):e199206

\section{RESUMO}

Objetivo: conhecer os sentimentos gerados na família pela internação hospitalar da criança. Métodos: estudo qualitativo, realizado no município do Rio Grande, com 21 familiares acompanhantes de crianças internadas, por meio de entrevista semiestruturada e dados tratados por análise temática. O estudo foi aprovado pelo Comitê de Ética em Pesquisa na Área de Saúde com o parecer favorável de número 92/2016. Resultados: verificaram-se que os familiares referiram medo do diagnóstico, desespero, preocupação, tristeza, ansiedade, desconforto e abatimento. Sentem-se mal e impotentes com a permanência da criança no hospital. Entretanto, entendem que nesse contexto serão fornecidos os recursos e o atendimento necessários. Considerações finais: o enfermeiro deve dar apoio e se fazer presente, desde o primeiro dia de internação da criança, a fim de auxiliar as famílias no cuidado mais qualificado à criança hospitalizada de forma harmônica.

Descritores: Criança hospitalizada; Família; Enfermagem

\section{ABSTRACT}

Objective: to know the feelings generated in the families by hospitalization of the child. Methods: qualitative study carried out in the city of Rio Grande, with 21 family members of hospitalized children, through a semi structured interview and data treated by thematic analysis. The study was approved by the Research Ethics Committee in the Health Area with favorable opinion of number 92/2016. Results: family members reported fear of diagnosis, despair, worry, sadness, anxiety, discomfort and depression. They feel bad and helpless with the child's stay in the hospital. However, they understand that in this context, the necessary resources and assistance will be provided. Final considerations: nurses should provide support and be present, since the first day of hospitalization of the child, in order to help families with the most qualified care to the hospitalized child in a harmonic way.

Descriptors: Child, hospitalized; Family; Nursing

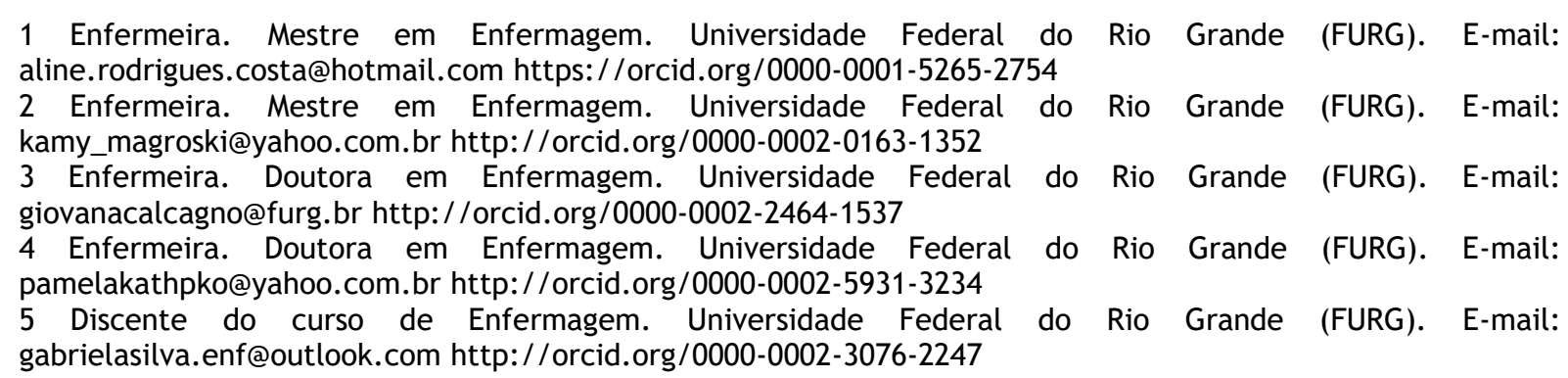




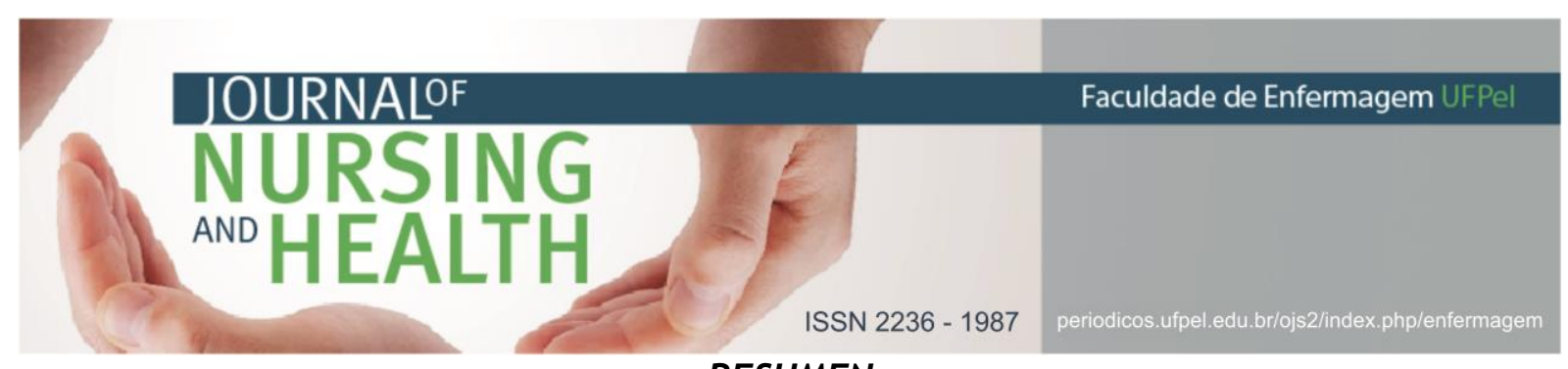

\section{RESUMEN}

Objetivo: conocer los sentimientos generados en la familia por la internación hospitalaria del niño. Métodos: estudio cualitativo, realizado con 21 familiares acompañantes, en el municipio del Rio Grande de niños internados, por medio de entrevista semiestructurada y datos analizados por medio del análisis temático. El estudio fue aprobado por el Comitê de Ética em Pesquisa en la Área de Salud con el dictamen favorable de número 92/2016. Resultados: los familiares refirieron miedo del diagnóstico, desespero, preocupación, tristeza, ansiedad, incomodidad y abatimiento. Se sienten mal e impotentes con la permanencia del niño en el hospital. Sin embargo, entienden que en ese contexto se proporcionarán los recursos y la atención necesarios. Consideraciones finales: el enfermero debe dar apoyo y hacerse presente desde el primer día de internación del niño, a fin de auxiliar a las familias en el cuidado más cualificado al niño hospitalizado de forma armónica.

Descriptores: Niño hospitalizado; Familia; Enfermería

\section{INTRODUÇÃO}

O adoecimento da criança é um momento que gera grandes mudanças e sentimentos conflitantes para o familiar cuidador. O hospital é um ambiente cercado por aparelhos, normas e rotinas desconhecidas que causam medo e estranheza ao paciente e seu acompanhante, ainda mais quando o mesmo é uma criança. Nesse contexto, cada familiar se encontra em situações e contextos distintos, com diferentes organizações, além de apresentar expectativas e experiências diversas diante da internação hospitalar da criança. ${ }^{1}$

A interação da família com os profissionais da saúde, seja no compartilhamento de informações ou nos cuidados referentes à saúde da criança e sua evolução tem sido objeto de estudo da enfermagem para observar como e a extensão dessa participação tem se dado no cotidiano assistencial. ${ }^{2}$ Nota-se que em diversas ocasiões a família fica em segundo plano, sendo o foco do trabalho da Enfermagem o cuidado centrado à criança e sua doença. Entretanto, o profissional vem tentando modificar a sua assistência, centrando-a também no cuidado a família que é a quem permanece ao lado da criança durante a sua hospitalização. ${ }^{3}$

O familiar cuidador necessita de orientação e deve ser encorajado a permanecer com a criança durante a hospitalização. ${ }^{4}$ Além disso, a boa comunicação entre equipe de enfermagem e família auxilia na redução da ansiedade, na aceitação destes frente a nova situação vivenciada, além de facilitar no tratamento, e favorecer o processo de enfrentamento da doença. ${ }^{4}$

A internação da criança, quando necessária, faz com que a família passe por um período de adaptação para conseguir lidar com essa nova situação. ${ }^{5} \mathrm{Na}$ maioria das vezes o cuidador responsável pela criança é a mãe que abre mão de suas atividades cotidianas e se dedica exclusivamente às necessidades do filho. ${ }^{5} \mathrm{Em}$ um estudo realizado em Minas Gerais (MG), evidenciou-se que para a mãe, acompanhar e participar do cuidado do filho representa a colaboração para a sua cura, minimizando o sentimento de culpa pela internação da criança. ${ }^{5}$

A presença de um profissional que esclareça as dúvidas, explique os 
cuidados realizados à criança e que se mostre presente pode fortalecer a estrutura familiar. Percebeu-se que a presença de uma equipe de enfermagem humanizada e participativa, contribui para a criação de um clima de bem-estar para os pacientes e acompanhantes, e para um bom relacionamento entre os familiares acompanhantes e 0 profissional. 6

A experiência da hospitalização da criança exige capacidade de enfrentamento e adaptação da família, pois as expectativas de que o filho seja saudável são frustradas quando este necessita ser internado. ${ }^{7} \mathrm{O}$ período de enfrentamento desses acontecimentos caracteriza-se por frustração e estresse que rompem a estabilidade familiar. $^{7}$ Assim, 0 enfermeiro necessita ser empático e compreensivo com a mesma, entendendo sua presença como um direito da criança, visto que é ela que conhece e tranquiliza a criança diante dos seus medos e inseguranças. Além de permitir a sua participação nos cuidados que normalmente já são prestados no domicílio. ${ }^{7}$

Logo, a prestação de cuidados frente as reais necessidades e sentimentos da família cuidadora refletir-se-á numa assistência de qualidade, favorecendo o estabelecimento de um cuidado integral à criança e ao seu acompanhante. É necessário que os profissionais da saúde se mostrem disponíveis, executando uma escuta atenta, proporcionando ações educativas de forma a instrumentalizar o familiar cuidador para o cuidado à criança. ${ }^{8}$ Além de mantê-los informados e participativos durante todo o processo de hospitalização. ${ }^{8}$

A assistência à família na Unidade de Pediatria é tema importante, e requer instrumentalização e qualificação constantes dos profissionais envolvidos a fim de proporcionar uma hospitalização humanizada à criança e seu familiar cuidador. ${ }^{8}$ Conhecer os sentimentos gerados frente a essa situação difícil pode auxiliar a prática profissional da Enfermagem de forma a atender as reais necessidades desse grupo.

Assim, a questão que norteou este estudo foi: quais os sentimentos gerados na família pela internação hospitalar da criança? O conhecimento gerado neste estudo poderá subsidiar aos profissionais que atuam em Unidades de Pediatria o desenvolvimento de estratégias efetivas de cuidado à criança e seu familiar cuidador, amenizando seu sofrimento durante 0 período de hospitalização. Portanto, o estudo objetivou conhecer os sentimentos gerados na família pela internação hospitalar da criança.

\section{MATERIAIS E MÉTODOS}

Trata-se de um estudo qualitativo, o qual trabalha com 0 universo de significados, motivos, aspirações, crenças, valores e atitudes. ${ }^{9}$ Além disso, permite que o pesquisador se envolva diretamente na situação e possibilita observar os agentes no seu cotidiano, convivendo e interagindo socialmente com estes. ${ }^{9}$

0 estudo foi realizado numa cidade portuária no sul do Rio Grande do Sul - Brasil, na Unidade de Pediatria 


\section{JOURNALOF \\ NURSING \\ ANO HEALTH}

ISSN 2236 - 1987

procedida com o uso de gravador de voz, em uma sala de forma individual. O tempo das entrevistas variou de acordo com cada participante em média 15 minutos. Os participantes foram abordados durante o período de internação da criança, informados sobre o objetivo do estudo e sua relevância para a saúde e para o grupo entrevistado. Para garantir o anonimato, as falas dos participantes foram identificadas pela letra $F$ seguida do número da entrevista.

Para a análise dos dados, utilizouse a técnica de Análise Temática. Foram três as etapas para o processo de análise: pré-análise - os dados foram ordenados e as entrevistas transcritas, preservando- se as falas na íntegra; descrição analítica - o material foi transcrito e agrupado em subcategorias; tratamento dos dados e interpretações, submetido a uma análise detalhada e exaustiva e depois organizado segundo categorias temáticas. ${ }^{9}$

0 estudo respeitou as exigências formais contidas nas normas nacionais e internacionais regulamentadoras de pesquisas envolvendo seres humanos. Foi aprovado pelo Comitê de Ética em Pesquisa na Área de Saúde da Universidade Federal do Rio Grande (CEPAS / FURG), com o parecer favorável de número 92/2016.

\section{RESULTADOS}

A seguir será apresentada a caracterização das participantes do estudo e a categoria gerada a partir da análise temática dos dados: sentimentos gerados na família pela internação hospitalar da criança. 


\section{JOURNALOF \\ NURSING \\ ANOHEALTH \\ Caracterização dos participantes do estudo}

Participaram do estudo 21 familiares acompanhantes de crianças internadas no período da coleta dos dados. Suas idades variaram entre 18 e 51 anos com uma média de 30,8 anos. Como grau de parentesco com a criança internada 19 eram mães e dois pais da criança. Quanto ao nível de escolaridade nove possuíam primeiro grau incompleto, dois com primeiro grau completo, um segundo grau incompleto, sete segundo grau completo e dois com ensino superior incompleto.

Em relação ao local de moradia, dois familiares residiam fora do munícipio, sendo um em Santa Vitória do Palmar e um em São José do Norte. Quanto ao número de filhos dois familiares possuíam cinco filhos, dois familiares possuíam quatro filhos, quatro familiares possuíam três filhos, sete familiares possuíam dois filhos e seis familiares possuíam um filho.

Quanto a idade das crianças internadas essa variou entre um mês e oito anos, com uma média de 6,9 anos de idade. Duas crianças internaram para realização de cirurgias, uma de apendicectomia e outra de plastia de tendão de membro inferior. Quatro internaram por bronquiolite, três por crises convulsivas, dois para tratamento de sífilis congênita, um por crise asmática, um por pneumonia, um por anemia profunda, um por edema periorbital a investigar, um por dor abdominal a investigar, um por edema em perna direita após queda, um por apresentar um tumor no rim direito já com metástases, uma criança
ISSN 2236 - 1987

encefalopata para tratamento de infecção urinária, um por gastroenterite e um por anóxia neonatal, esta permanece internada desde o seu nascimento.

Sentimentos gerados na família pela internação hospitalar da criança

Quanto aos sentimentos gerados durante a internação da criança um familiar cuidador referiu sentir medo frente ao diagnóstico da criança por nunca ter vivenciado situação semelhante na família.

Quando soube lá com o doutor que ela estava com anemia profunda, eu fiquei com medo que desse leucemia. Eu chorei muito. Eu fiquei com muito medo, porque é a primeira que teve alguma coisa, porque a minha outra nunca teve nada, a não ser essas gripezinhas, normal. Ficar baixada no hospital ela nunca ficou. (F2)

Diante da internação da criança, muitas vezes, a família não sabe como lidar com a situação o que interfere no seu estado emocional, causando o desespero. Esse sentimento unido com o da preocupação foi relacionado ao afastamento dos demais filhos, tendo que deixá-los aos cuidados de outras pessoas.

Nem sei o que se passa pela minha cabeça. Está sendo um desespero. (F19)

Desesperador porque o outro irmão dela só fica comigo, entendesses. Ele não interage 


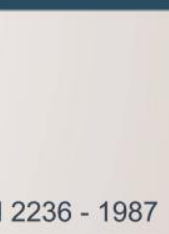

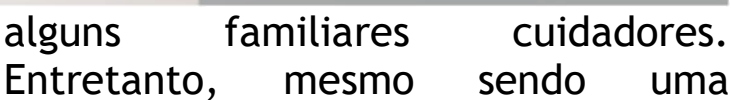
situação difícil, os familiares consideram a internação importante para a saúde da criança, visto que naquele ambiente a mesma terá a assistência necessária para a recuperação dessa saúde.

Bem nervosa porque era sinal de que ele não estava muito bem mesmo que nem eu achava. Mas depois ficou tranquilo porque era para o bem dele. (F8)

Eu me senti, assim, para baixo né. Porque em casa estou com ela tudo bem e aqui ela está bem, mas não está a mesma coisa do que comigo em casa. (F1)

Ansiedade, ah sei lá, tu ficas presa aqui. $\dot{E}$ angustiante. Em casa tu estás mais à vontade, mas fazer o quê? (F4)

Meio desconfortável. A gente não gosta de passar por isso, mas fazer o quê? A gente gosta de estar na nossa casa. É para o bem dele. (F17)

É difícil porque eu a vejo chorando. Porque ela tinha aquela coisa de brincar, de correr, de ter aquela liberdade dela. $E$ vê ela assim choramingando, sentindo falta dos irmãos. Quer brincar e não pode. Mas não por estar aqui dentro porque eu sei que é o melhor para ela. Isso não me abateu. Me abateu só isso de ver ela, de ver que ela quer sair e não pode. Isso é desconfortável. (F9) 
Achei ruim porque acho que não precisava. Mas é para o bem dele então a gente entende. (F21)

Verificou-se que a família se sente mal $e$ impotente com a permanência da criança no hospital. A falta de previsão da cura e da alta e o desejo de estar no lugar da criança para evitar que ela passe por esse período foram apontados pelos familiares cuidadores.

É uma sensação assim ó, tu tens que ficar, tu tens que aceitar porque tu não podes fazer nada. Eu não tenho o oxigênio, não tenho o remédio, não estudei para isso, não estou preparada para cuidar. Tu aceitas, tu não tens outra opção, tu precisas que a criança seja tratada, tu precisas que a criança seja atendida. São coisas que fogem ao recurso de uma mãe e um pai, por mais que eu queira. (F3)

O sentimento que passa é como eu te falei, a gente não quer que aconteça com eles. Eu já tive um leve período aqui dentro. Então a gente se sente uma pessoa, como é que eu vou te dizer? A gente se sente mal, a gente não quer que aconteça com eles. A gente quer que aconteça conosco, mas não com eles. A gente se sente meio impotente. Mas não tem o que fazer. Eu falei para ela, não tem o que fazer, tem é que ficar quietinha agora, fazer tudo direitinho para ir o mais rápido para casa. (F15)
Ah mal, muito mal porque nenhuma mãe quer ver um filho internado. (F2)

Ah, eu me senti mal. Me deu um aperto no peito ver minha filha no hospital. Não sabendo se vai demorar para curar ou não. Mas eu prefiro ficar aqui porque ela cura mais rápido. (F12)

Mesmo o momento da internação sendo um período difícil pode-se observar que dois familiares cuidadores se sentem mais tranquilos no hospital. Entendem que ali estão concentrados os recursos e o atendimento necessários e que, sem isso, no domicílio podem ocorrer complicações mais graves pela falta de tratamento adequado.

É que assim: na hora é mais tranquilo estar dentro do hospital do que em casa, porque ela é assim as $24 \mathrm{~h}$ dela é as $48 \mathrm{~h}$ de uma criança normal, entendesses? O dela é tudo mais acelerado, então não adiantava eu ir para casa e ela vir pior do que ela já estava. Então para mim foi tranquilo ter que ficar aqui. Infelizmente assim: tu não queres estar aqui dentro, mas foi bem melhor estar aqui dentro do que eu voltar com ela em estado mais grave. (F14)

Aqui eu estou mais tranquila porque eu sei que ela não está com manchinha no pulmão. 0 pulmão dela está limpinho, sabe? Mas daquela outra vez eu já fiquei mais preocupada porque ela estava quase morrendo mesmo. Foi grave! (F16) 


\section{NURSING \\ AND \\ HEALTH}

Constatou-se que um dos familiares cuidadores não aceita a situação clínica da criança, visto que esta permanece internada desde o seu nascimento. Porém, apesar desse sentimento foi preciso a adaptação da família ao longo do tempo às circunstâncias presentes.

Foi horrível ter que voltar para casa e deixar ele aqui. Foi bem complicado. Eu não tinha vontade de ir para casa. As coisas dele, a bolsa dele eu levei meses para desfazer. Foi bem difícil. Com o tempo tu vais te adaptando. Tu não aceitas, mas tu sabes que tu tens que passar por aquilo ali. Tu sabes que tu tens que ser forte, ele depende da gente. Tu não vais abandonar, ele não tem defesa nenhuma. Mas é desesperador. Parece que tem dias que tu não vais conseguir. (F13)

\section{DISCUSSÃO}

Os sentimentos frente à internação hospitalar para a família são diversificados e intensos, interferindo durante esse período tão delicado. 0 ambiente hospitalar pode gerar sentimentos de ameaça, agressão, medo do desconhecido, pois é durante esse momento que a criança e a família se sentem afastadas de todos os objetos e vivências significativas do seu cotidiano. ${ }^{6}$

O familiar cuidador ao se deparar com a notícia da internação da criança sofre junto com ela, se sente angustiado e com dificuldades em lidar com seus próprios sentimentos. A necessidade de internação da criança faz com que a família entre em um
ISSN $2236-1987$

mundo desconhecido e novo que ocasiona diversos sentimentos como o medo, a ansiedade e a culpa. ${ }^{1}$

Em um estudo realizado em uma Unidade de Terapia Intensiva Pediátrica na região Sul do Brasil, os familiares cuidadores referem que a angústia e o medo são sentimentos que surgem no momento em que a família começa a "se dar de conta" da verdadeira extensão do problema, entendendo a natureza da situação a ser enfrentada. ${ }^{11}$ São manifestações da incerteza da condição futura da criança e de busca de causas, as quais incluem a sua própria atuação e o tempo para o diagnóstico. ${ }^{12}$

A presença constante do familiar cuidador na hospitalização da criança é um fator que modifica toda a sua rotina familiar. Em determinadas situações o responsável pela criança é o principal provedor de renda no lar e com a necessidade de internação precisa muitas vezes abandonar seu emprego ou realizar uma jornada dupla entre a criança e o trabalho para manter o sustento da família. ${ }^{12}$ Além disso, a falta de recursos financeiros e os gastos excessivos com a hospitalização da criança, pode ocasionar em algumas situações desequilíbrio no orçamento da família, gerando sentimentos de desmotivação e estresse. ${ }^{1}$

O confinamento do familiar cuidador no hospital afeta a sua convivência com os demais familiares o que interfere de forma negativa, principalmente quando existem outros filhos envolvidos. Essa separação do seu lar e das suas rotinas cotidianas geram muitos sentimentos e mudanças que podem influenciar no 


\section{IOURNAIOF

relacionamento familiar, deixando esse grupo vulnerável. ${ }^{6}$

Sendo assim, por não ter o auxílio de outros integrantes do núcleo familiar, o cuidador necessita deixar os demais filhos sob os cuidados de vizinhos, conhecidos, amigos ou de pessoas contratadas especialmente para esse fim. ${ }^{12}$ Essa situação pode gerar sentimento de culpa ou até mesmo dificuldades financeiras. A tristeza e desespero frente à necessidade da internação da criança podem surgir durante esse período. A família, principalmente quando a internação ocorre pela primeira vez, pode manifestar culpa, insegurança, angústia, além da sensação de fracasso e impotência na sua função de cuidadora e de promotora da saúde e bem-estar da criança. ${ }^{1-12}$

Apesar da hospitalização da criança apresentar-se como um momento complicado na vida da família, ela reconhece o ambiente como um lugar onde a criança terá os recursos necessários para ser assistida. ${ }^{6}$ A família demonstra alívio e tranquilidade por saber que naquele ambiente a criança será atendida e terá o tratamento disponível. Além disso, em situações onde existe diagnóstico de doenças crônicas, em que há necessidade de uma permanência maior no hospital e pelas recorrentes hospitalizações, os profissionais e as famílias possuem oportunidade de estabelecer uma relação de proximidade, melhorando a adaptação à situação vivenciada. ${ }^{13}$

A negação é um dos sentimentos que podem surgir durante a hospitalização da criança. É vista como uma defesa que o familiar adquire frente ao diagnóstico obtido, muitas vezes passando a duvidar dos exames, da competência da equipe e associada à raiva o torna instável, o que pode interferir de forma negativa na convivência com a equipe na unidade. ${ }^{12} \mathrm{Um}$ estudo realizado em uma Unidade de Terapia Intensiva Pediátrica no Rio Grande do Sul evidenciou que em situações de adoecimento, a negação pode ser externalizada enquanto mecanismo de defesa, dependendo do nível de preparo da família no que tange ao processo de morte e morrer. ${ }^{12} \mathrm{~A}$ família da criança diagnosticada com uma doença grave, possivelmente fatal, pode desencadear 0 processo de negação. ${ }^{14}$

A hospitalização e as situações referentes à patologia da criança podem contribuir nas reações apresentadas pela família. Portanto, a existência de uma boa comunicação dentro da unidade de internação auxilia na relação e na convivência da equipe com a família, e quando há a presença do respeito e valorização do discurso do outro, é possível verificar a construção de relações baseadas no afeto e na criação de vínculo. ${ }^{15}$

Os sentimentos negativos frente à nova condição da criança podem ser minimizados se os familiares receberem as orientações necessárias acerca do diagnóstico e dos cuidados que a criança deverá receber. ${ }^{16}$ Logo, faz-se necessário a presença de profissionais capacitados e humanizados para a prestação de uma assistência de qualidade também a família, pois esta passa todo o período de internação ao lado a criança. Essas considerações remetem à necessidade 
de estabelecer um espaço de escuta e de fala para a família expressar sua vivência, fazendo com que os profissionais de saúde reflitam e se mobilizem no sentido de minimizar o sofrimento da família durante o período da internação hospitalar da criança. ${ }^{16}$

\section{CONSIDERAÇÕES FINAIS}

O objetivo do presente estudo foi conhecer os sentimentos gerados na família pela internação hospitalar da criança. Assim, percebeu-se que os familiares cuidadores entrevistados referiram sentir medo frente ao diagnóstico da criança por nunca ter vivenciado situação semelhante. 0 sentimento de desespero unido com o da preocupação foi relacionado ao afastamento dos demais filhos tendo que deixá-los aos cuidados de outras pessoas. A tristeza, ansiedade, desconforto de estar em um ambiente diferente do habitual e o abatimento diante da necessidade de internação também foram mencionados por alguns familiares cuidadores. Verificou-se também que a família se sente mal e impotente com a permanência da criança no hospital. Entretanto, mesmo o momento da internação sendo um período difícil pode-se observar que dois familiares cuidadores se sentem mais tranquilos no hospital por entenderem que ali serão fornecidos os recursos e o atendimento necessários do que no domicílio. Constatou-se que a não aceitação da situação clínica da criança mostrou-se presente em um dos participantes do qual a criança permanece em internação desde o seu nascimento.
Conclui-se, por meio dos dados obtidos, é importante a equipe conhecer os sentimentos da família acerca da internação da criança, visto que por meio desta percepção, a equipe pode criar estratégias que visem um cuidado humanizado não só com a criança, mas também para a família, que é a sua principal fonte de cuidados.

Como limitações do estudo, percebe-se que a enfermagem ainda é omissa no cuidado ao acompanhante da criança internada, tratando-a muitas vezes como mão de obra de cuidado. Assim, necessita-se de um olhar atento dos profissionais para as questões que envolvem o bem-estar desse familiar durante esse período difícil.

\section{REFERÊNCIAS}

1 Pozzatti R, Diaz CMG, Backes DS, Freitas HMB, Costenaro RGS, Zamberlan C. Enfrentamento da internação da criança em uti-ped pelo familiar/cuidador.

Revista Disciplinarum Scientia [Internet]. 2017[acesso em 2019 jun 11];18(1):157-68. Disponível em: https: / / periodicos.ufn.edu.br/index.p $\mathrm{hp} /$ disciplinarumS/article/view/2259/ 2023

2 Chagas MCS, Gomes GC, Pereira FW, Diel PKV, Farias DHR. Significado atribuído pela família ao cuidado da criança hospitalizada. Av. enferm. [Internet]. 2017[acesso em 2019 mar 25];35(1):7-18. Disponível em: http://www.scielo.org.co/pdf/aven/v 35n1/v35n1a02.pdf

3 Silva JL, Santos EGO, Rocha CCT, Valença $\mathrm{CN}$, Júnior OGB. Organização 
do trabalho de enfermagem diante da inserção dos cuidados familiares com a criança hospitalizada. Rev Rene (Online). [Internet]. 2015[acesso em 2019 mar 25];16(2):226-32. Disponível em:

http: / /www.repositorio.ufc.br/bitstre am/riufc/12656/1/2015_art_jlsilva.pd $\mathrm{f}$

4 Gonçalves KG, Figueiredo JR de, Oliveira SX, Davim RMB, Camboim JCA, Camboim FEF. Hospitalized child and the nursing team: opinion of caregivers. Rev. enferm. UFPE on line. [Internet]. 2017[cited 2019 Mar 26];11(Suppl.6):2586-93. Available from:

https: / / periodicos.ufpe.br/revistas/r evistaenfermagem/article/view/2342 7/19115

5 Ramos DZ. Family participation in the care of children hospitalized in an intensive care unit. Rev. bras. promoç. saúde (Impr.). [Internet]. 2016[cited 2019 Mar 25];29(2):189-96. Disponível em:

https: / / periodicos.unifor.br/RBPS/art icle/view/4361/pdf_1

6 Andrade CR, Maciel AA. A internação conjunta: vivência de acompanhantes de crianças hospitalizadas. Revista norte mineira de enfermagem [Internet]. 2016[acesso em 2019 mar 25];5(1):05-23. Disponível em: http://www.renome.unimontes.br/in dex.php/renome/article/view/138/14 2

7 Macedo IF, Souza TV, Oliveira ICS, Cibreiros SA, Morais RCM, Vieira RFC. Nursing team's conceptions about the families of hospitalized children. Rev. bras. enferm. [Internet]. 2017[cited 2019 Mar 25];70(5):952-60. Available from:

http://www.scielo.br/pdf/reben/v70 n5/0034-7167-reben-70-05-0904.pdf

8 Gomes GC, Xavier DM, Pintanel AC, Farias DHR, Lunardi VL, Aquino DR. Meanings attributed by family members in pediatrics regarding their interactions with nursing professionals. Rev. Esc. Enferm. USP. [Internet]. 2015[cited 2019 Mar 25]; 49(6):953-9. Available from: http://www.revistas.usp.br/reeusp/a rticle/view/108416/106715

9 Minayo MCS. Pesquisa Social; teoria, método e criatividade. 29 ed. Petropólis: Vozes; 2010.

10 Fontanella BJB, Ricas J, Turato ER. Amostragem por saturação em pesquisas qualitativas em saúde: contribuições teóricas. Cad. Saúde Pública (Online). [Internet]. 2008[acesso em 2019 mai 13];24(1):17$27 . \quad$ Disponível em: http://www.scielo.br/pdf/csp/v24n1 102.pdf

11 Pêgo CO, Barros MMA. Unidade de Terapia Intensiva Pediátrica: expectativas e sentimentos dos pais da criança gravemente enferma. Rev. bras. ciênc. saúde. [Internet]. 2017[acesso em 2019 mar 25];21(1):1120. Disponível em: http://www. periodicos.ufpb.br/index .php/rbcs/article/view/23827/16430

12 Barreto TSM, Sakamoto VTM, Magagnin JS, Coelho DF, Waterkemper $\mathrm{R}$, Canabarro ST. Experience of parents of children with congenital heart disease: feelings and obstacles. Rev Rene (Online). [Internet]. 2016 [cited 2019 Mar 26];17(1):128-36. Available from: 


\section{NURSING \\ ${ }^{\text {AND HEALTH }}$}

http://repositorio.ufc.br/bitstream/ri ufc/16188/1/2016_art_tsmbarreto.pdf

13 Machado AN, Nóbrega VM, Silva MEA, França DBL, Reichert APS, Collet N. Chronic disease in children and adolescents: professional-family bond for the promotion of social support. Rev. gaúch. enferm. [Internet]. 2018[cited 2019 Mar 26];39:e20170290. Available from: http://www.scielo.br/pdf/rgenf/v39/ en_1983-1447-rgenf-39-e2017-

0290.pdf

14 Genovesi FF, Ferrari RA. Experiencia materna frente al tratamiento del cáncer de su hijo. Rev. urug. enferm. [Internet]. 2015[acesso em 2019 mar 26];10(1):11-21. Disponível em: http://rue.fenf.edu.uy/index.php/rue /article/view/3/2

15 Azevêdo AVS, Júnior ACL, Crepaldi MA. Nursing team, family and hospitalized child interaction: an integrative review. Ciênc. Saúde Colet. [Internet]. 2017[cited 2019 Mar 26];22(11):3653-66. Available from: http://www.scielo.br/pdf/csc/v22n11 /en_1413-8123-csc-22-11-3653.pdf

16 Gomes GC, Nornberg PKO, Jung BC, Nobre CMG, Rodrigues EF, Xavier DM. Chronic disease in children: family experience in diagnostic reception. Rev. enferm. UFPE on line. [Internet]. 2016[cited 2019 Mar 26];10(Suppl.6):4837-44. Available from:

https: / / periodicos.ufpe.br/revistas/r evistaenfermagem/article/view/1126 $3 / 12891$ 